\title{
A Promising Way of Resource Utilization in China: Converting Waste Oils and Fats to Biodiesel
}

\author{
Shitao Liu, Congping Wu \\ Kunshan Innovation Institute of Nanjing University, Kun Shan, China \\ Email: liust@njukii.com, 2cpwu@nju.edu.cn
}

Received February 2014

\begin{abstract}
Most of Biodiesel, a clean burning alternative fuels for diesel engines is made from renewable agricultural feedstock, such as rapeseed oil, soybean oil etc., but less expensive biodiesel can also be made from waste oils and fats, including recycled restaurant grease and animal fats. Because of the eating habit of the nation and diet culture in china, restaurant-kitchen garbage is increasingly serious and has negative impact on environment and food security. The utilization of waste oils and fats to biodiesel provide a promising way of how to appropriately and effectively dispose of restaurant-kitchen garbage. This paper first reviews the development status of biodiesel industry, then introduces the novel technology of tubular reaction for producing biodiesel from waste oils and fats on the typical industrialization case in Kunshan. All these efforts are expected to provide a viable development path for our waste oil to produce biodiesel and worth reference to waste oils and fats recycling and reuse.
\end{abstract}

\section{Keywords}

Resource Utilization, Waste Oils and Fats, Tubular Reaction, Biodiesel

\section{Introduction}

Transportation sector is one of resource of three major greenhouse-gas emissions, and fuel consumption is the greatest contributor within transportation pollution. The automotive fuel is increasingly dependent on petroleum resources, more than 95\% of it derived from gasoline and diesel fuel oil in China. Along with fuel consumption growing exponentially, influenced by world oil resources, fluctuating oil price, environment protection and the global climate change, more and more countries are encouraging the production and utilization of bio-liquid fuels as alternative fuel to meet the need of automobile energy supply while fulfill the targets of greenhouse reduction.

Bio-liquid fuels refer to the liquid fuels produced by physical, chemical and biological technology using renewable biomass resources as raw materials, including methanol, ethanol, biodiesel and other liquid fuels, which is the important international direction of biomass energy industry. At present, some of the bio-liquid fuel prod- 
ucts, such as fuel ethanol and biodiesel have begun to promote usage and popularization. The production technology of fuel ethanol is growing fastest and its production facility is also most mature, with the largest scale production after petrochemical industry, but the problem is that fuel ethanol can be used as a burning alternative fuels for existing gasoline engines only when anhydrous ethanol (purity $>99.3 \%$ ) mixed up with gasoline by a certain percentage (ethanol content $<25 \%$ ), which greatly limits its market and popularization. By contrast, as a clean burning alternative fuels, because it can be used directly in the current diesel engine system, the combustion performance is more superior to petrochemical diesel, and safer production, storage and transportation, biodiesel is honored as "liquid solar energy", considered to be one of the most valuable liquid biomass energy [1].

This paper first review the development status of biodiesel industry, then introduce the novel technology of tubular reaction for producing biodiesel from waste oils and fats on the typical industrialization case in Kunshan. All these efforts are expected to provide a viable development path for our waste oils and fats to produce biodiesel and worth reference to waste oils and fats recycling and reuse.

\section{The Development Statue of Biodiesel Industry}

The 1973 oil embargo and crisis stimulated a rapid rise in industrialized production of biodiesel. Over the past two decade, the biodiesel industry has steadily grown and achieved an advanced stage as a commercial technology, especially in the United States with biodiesel plants now in nearly every state in the country.

\subsection{Overall Picture of Biodiesel Industry}

Currently, there are about 28 world countries committed to research and production of biodiesel [2]. According to the statistical data of EIA [3], the biodiesel production capacity in the world reached to nearly 1,897,000 barrels day ${ }^{-1}$ in 2011, and EU which dominated by France and Germany is approximately 6.2\%, US was about $51.2 \%$, Brazil was $23.1 \%$, Argentina was $2.7 \%$. The Figure 1 is the trend graph on biodiesel production in 2007-2011. No double, the United States in the field of energy development is once again leading the world.

Meanwhile, along with most countries attaching much value to the important role of low carbon automotive fuels in emission reduction and climate change mitigation, there is a continuous increasing demand for biodiesel as a substitute for fossil fuel. The Figure 1 also shows the increased biodiesel consumption during recent years. As predicted, the supply-demand relations will be imbalanced.

The global demand for biodiesel is expected to grow rapidly until at least 2020, because of consumption mandates and high energy prices. Most of the growth is expected to come from the United States and the European Union (EU), because both have mandated large increases in biofuel consumption.

\subsection{The Biodiesel Development Situation in China}

Until the People's Republic of China renewable energy law was promulgated in 2005, the industrialization of

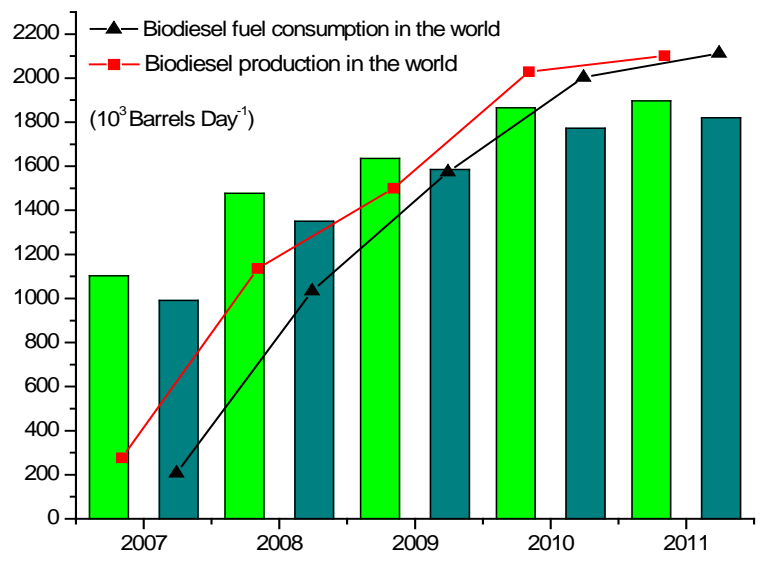

Figure 1. The biodiesel oil supply and demand in the world in 2007-2011. 
biodiesel has entered a stage of large-scale.

Biodiesels production in China starts late, but they developed quickly. By the end of 2006, China's biodiesel production companies have 25, the production capacity has reached 1.2 million t/a [4]. Figure 2 is a recent change of biodiesel production in china [5]. It indicates that our biodiesel industry is constantly moving forward, but there still have a big gap in the world from the average rate of growth. From 2006 to 2011, China's average growth rate of biodiesel is 7.9\% higher than the veteran producer Germany 6 percent, but still below the world average growth rate of $17.68 \%$, while the same for the emerging biodiesel producing countries, Thailand is $49 \%$, Singapore is $10.76 \%$.

Of course, compared with foreign countries, China still has some gaps in development of biodiesel that its industrial scale is still small, averaging less than 20,000 tons/year. It mainly caused by the current policy of not mandatory, biodiesel is still not entering the field of energy circulation, Shortage of raw material supply and other reasons. However, with the emphasis on national energy and environmental issues, our biodiesel industry will eventually grow.

It is predicted that by 2020, the production of biodiesel will reach 9,000,000 tons. Within the next twenty or thirty years, the scale of the use of biodiesel in china will exceed the current level of developed countries [6]. So the prospect of development of biodiesel is very considerable.

\section{The Novel Technology of Tubular Reaction for Producing Biodiesel from Waste Oils and Fats}

As continuous investment and research goes deep, biodiesel industry around the world in lots of aspect, such as the raw material origin, preparation technique and the reaction devices etc. have changed significantly.

\subsection{The Popular Technical Route to Produce Biodiesel Production}

The existing widely used technical route of producing biodiesel around the world is extracting grease firstly from a biodiesel feedstock and then makes the appropriate conversion technology to produce biodiesel. The extracted oil raw material, however, often with long carbon chain and large molecular weight, higher viscosity at room temperature, volatile poor, is not suitable for direct use in diesel engine [7].

In order to reduce the viscosity of grease, to improve its flow properties for achieving the requirements of existing diesel engines, a lot of research had been made for its modification. Concrete can be summarized as two categories, one is physical method of direct use and blending and emulsions, and the other is chemical methods of thermal cracking and transesterification [8].

The main biodiesel production technology is given priority to the chemical method, transeterification of vegetable oil (or animal oil) and methanol (or ethanol) catalyzed by acid, alkali or enzymes catalyst with resulting

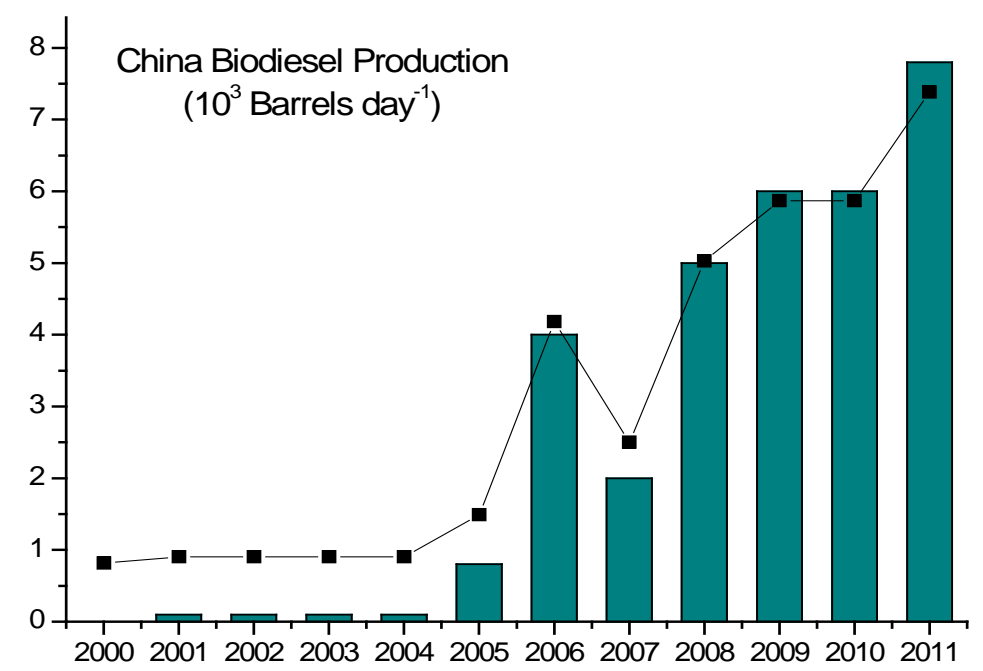

Figure 2. 2000-2011 the change of biodiesel production in china. 
corresponding products called fatty acid methyl esters (FAME) or ethyl ester fuel oil (Figure 3).

Transesterification is an available method to produce biodiesel. However, it must take long reaction time, consume much more energy and raw materials during the reaction so that add to the cost of production, and the high cost is the main hurdle to commercialization of the products.

\subsection{The Innovation Processing Technology of Biodiesel}

Based on the problems existing in the conventional production process, the United States developed Mcgyan process which is a new type of fixed-bed tubular reactor with filling of solid catalyst. The process (shown in Figure 4) is not sensitive to moisture and free acid in raw material, at the same time, the reaction can be com-

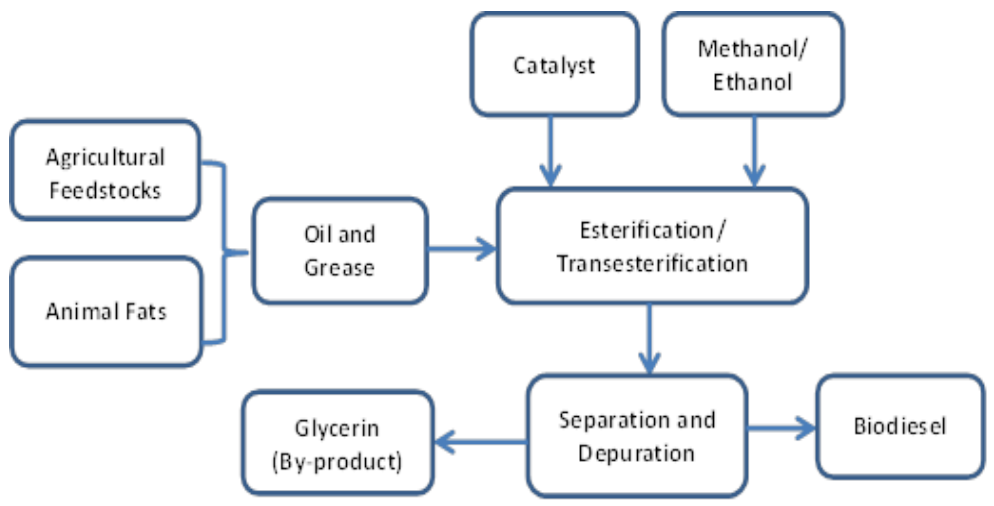

Figure 3. The general technologies of production of biodiesel fuel.

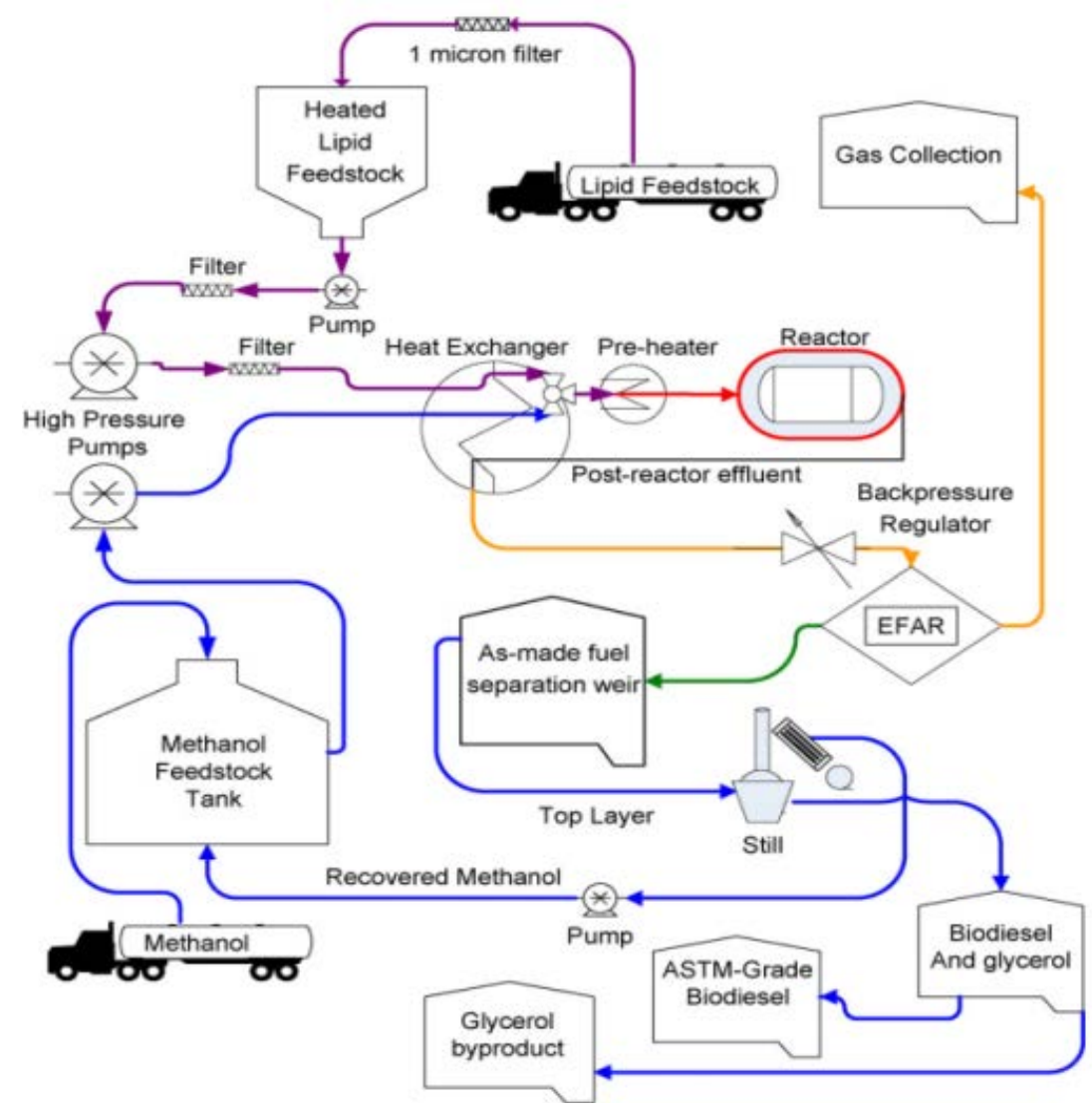

Figure 4. Process flow diagram of a biodiesel plant based on the Mcgyan process. 
pleted in only a few seconds, when the reaction is end, the production and catalyst will automatically separate, and can get ASTM standard of biodiesel without clean separation [9]. Because it is simpler, low demand for raw materials and high utilization of raw materials, in 2009, an annual output of 3 million gallons of biodiesel industrial production line which uses the process has been built in the United States [10].

However, the reaction conditions $\left(300^{\circ} \mathrm{C}-450^{\circ} \mathrm{C}, 17 \mathrm{MPa}\right)$ put forward high request to equipment, thus increasing the manufacturing costs and also the risk of equipment operation, while the process need to consume large amounts of energy. So in order to solve the problems in the process, we have developed a new type of tubular reactor system to produce biodiesel in its original process, and successfully developed $\mathrm{ZrO}_{2}$ polycrystalline ceramic foam catalyst. The process is shown in Figure 5.

Compared with the Mcgyan process, this process not only retains the advantages of Mcgyan process, but also solves the problems of it. In addition, the process has higher degree of system integration, device smaller, and can produce biodiesel in a moving truck. While compared with other solid catalysts, $\mathrm{ZrO}_{2}$ polycrystalline ceramic foam catalyst has many advantages, such as the production process is simple, high mechanical strength, good stability, high catalytic efficiency, long service life, etc. At the same time, it can achieve 98\% biodiesel conversion rate and a purity of about $96 \%$ glycerol only in 10 to 15 minutes, while the reaction temperature dropped to $275^{\circ} \mathrm{C}-290^{\circ} \mathrm{C}$ and pressure drops to 8 - $10 \mathrm{MPa}$. Thus, the process has further reduced the production cost, while also reduced the pollution of the environment.

\section{The Utilization of Waste Oils and Fats to Biodiesel}

Most of the traditional biodiesel producing was conducted with agricultural feedstock, such as rapeseed oil, soybean oil etc., as raw material, the cost of raw material covers about $80 \%$ of the production cost. The economic competitiveness of biodiesel industry depends largely on raw materials species, production area and climate conditions. Thus, the renewable fuel commercially refined from more inexpensive and a diverse array of raw material is the key of the development of biodiesel.

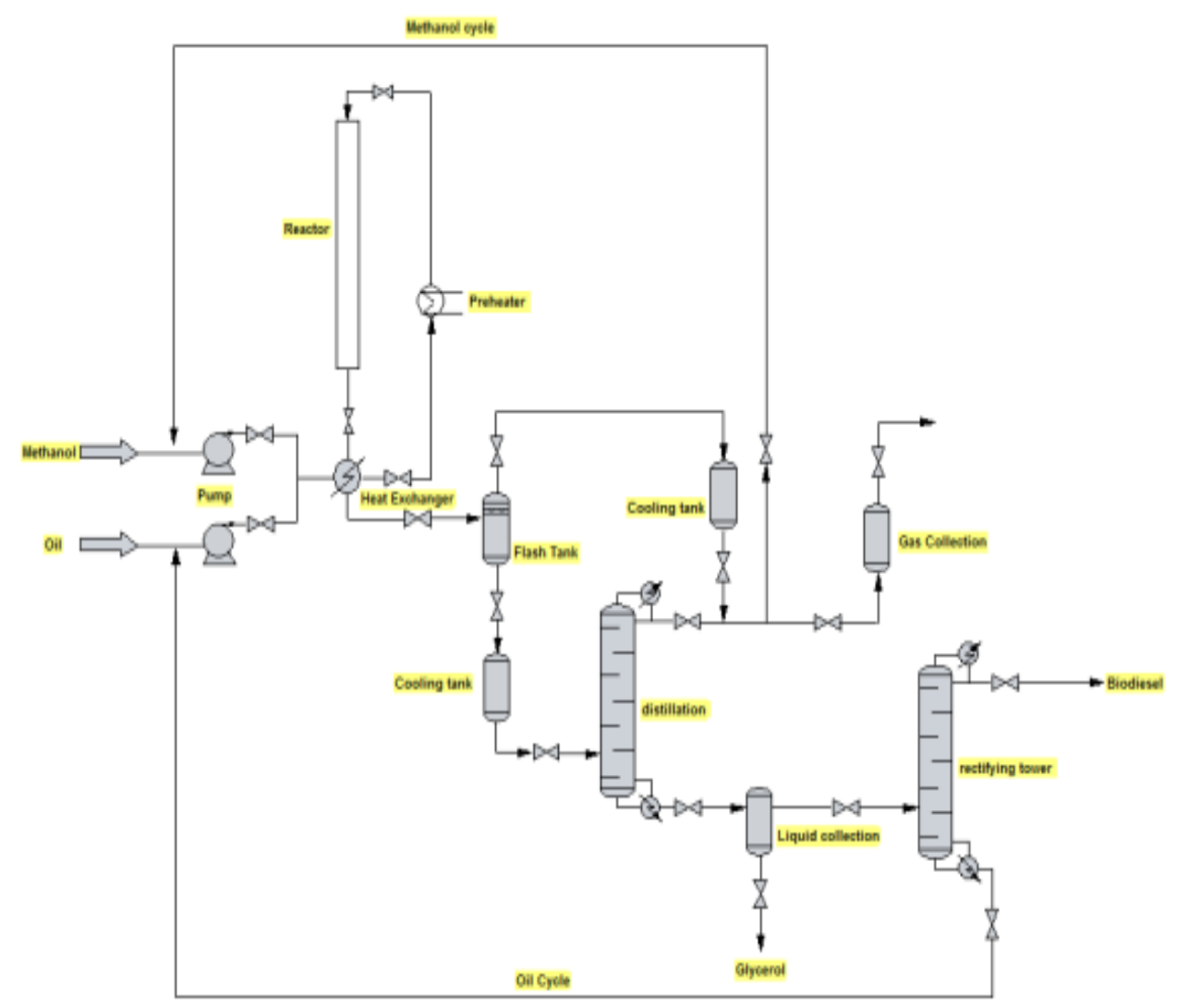

Figure 5. The route of production biodiesel by tubular reaction system. 


\subsection{The Production Technology of Biodiesel from Waste Oils and Fats}

With the largest population in the world and the larger demand for food oil, raw material for biodiesel production mainly depends on the development of non-edible oil raw material, such as small seed of tung tree, pistacia which are cultivated without farmland occupation, and by-products of producing food for human and animal consumption.

Because of the eating habit of the nation and diet culture in china, restaurant-kitchen garbage is increasingly serious and has negative impact on environment and food security. The utilization of waste oils and fats to biodiesel provide a promising way of how to appropriately and effectively dispose of restaurant-kitchen garbage.

The oil crops research institute of the Chinese academy of agricultural sciences has succeeded in the efficient esterification reaction of free fatty acids in the waste oils and fats and transesterification reaction, using the technology of azeotropic distillation glyceride-methyl esterification, thus opening a new path for the utilization of waste oils and fats to biodiesel [11]. However, adding azeotropic distillation solvent does not change its essence of traditional production method of acid-base two steps, so it have to solve the problems of traditional process, such as corrosion of equipment, need neutralization, water washing to remove catalyst after reaction, waste of water resources and the pollution of the environment, etc. and up to 4 hours of reaction time is not conducive to industrial production. While the sub-critical methanol alcoholysis process (SRCA process) was developed by SINOPEC Research Institute of Petroleum Processing for producing biodiesel from Waste oils and fats solves the problem of raw material refining process, and reached more than $95 \%$ conversion efficiency under the reaction conditions $260^{\circ} \mathrm{C}-280^{\circ} \mathrm{C}, 6$ - $8 \mathrm{MPa}$ [12]. Unfortunately, the additional co-solvent is not only introducing new production costs, but also increases the difficulty of separation and purification.

To this end, we introduce the new tubular reactor to produce biodiesel from waste oils and fats. Compared with other processes, the range of raw materials in the technology is broader, and it is not sensitive to moisture and acid value of raw materials. Meanwhile, in order to verify the process also can use to waste oil and fats, the two main indexes of waste oil and acid were studied. In Figure 6, the influence of raw material moisture content impact on catalyst activity is not evident, and when the moisture content is $7.10 \%$ which is already very close to the waste oil and fats [13], the conversion rate into a slight decline, but the decline is not large, compared with the $5.10 \%$ only decline $3.79 \%$, the yield is still above $93 \%$.

The same result can be obtained from Figure 7, with an acid number increases, the content of fatty acid methyl ester in product is maintained at a substantially straight line, even if the acid value reached $130.70 \mathrm{mg} / \mathrm{g}$ $\mathrm{KOH}$, the transesterification yield can still reach $97.67 \%$.

Experimental results show that the new tubular reactor system is fully capable of waste oils and fats as feedstock for biodiesel production. Thereby it has opened up a new way for waste oils and fats to biodiesel and reduces the production cost of biodiesel in our country.

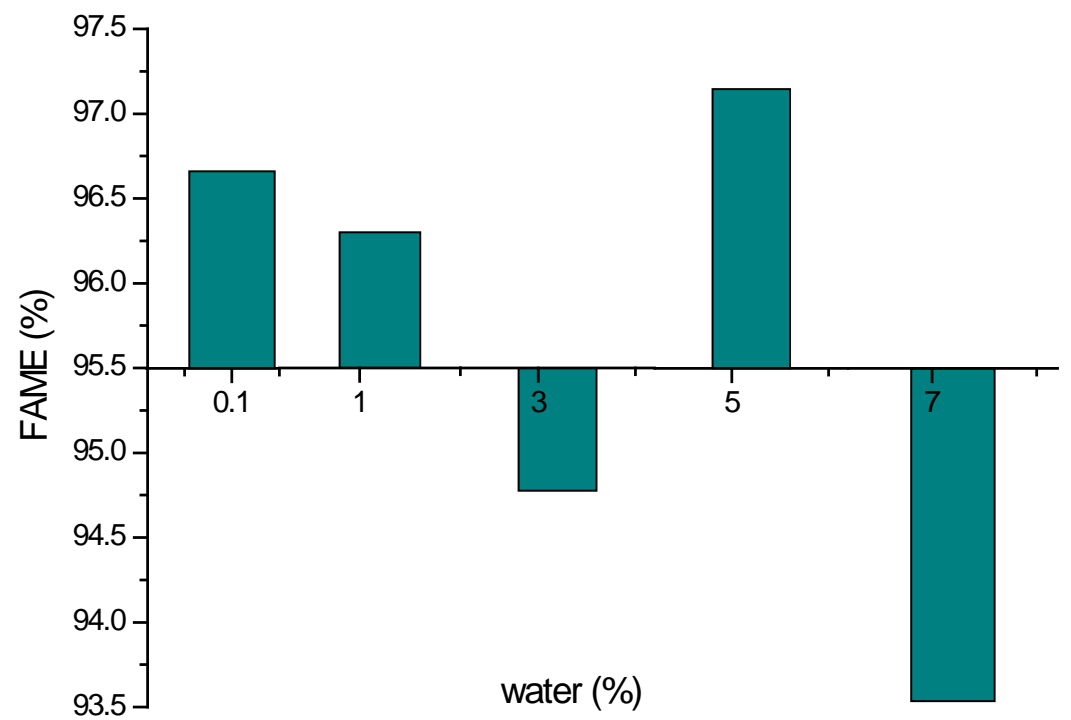

Figure 6. The influence of water on the content of fatty acid methyl ester. 


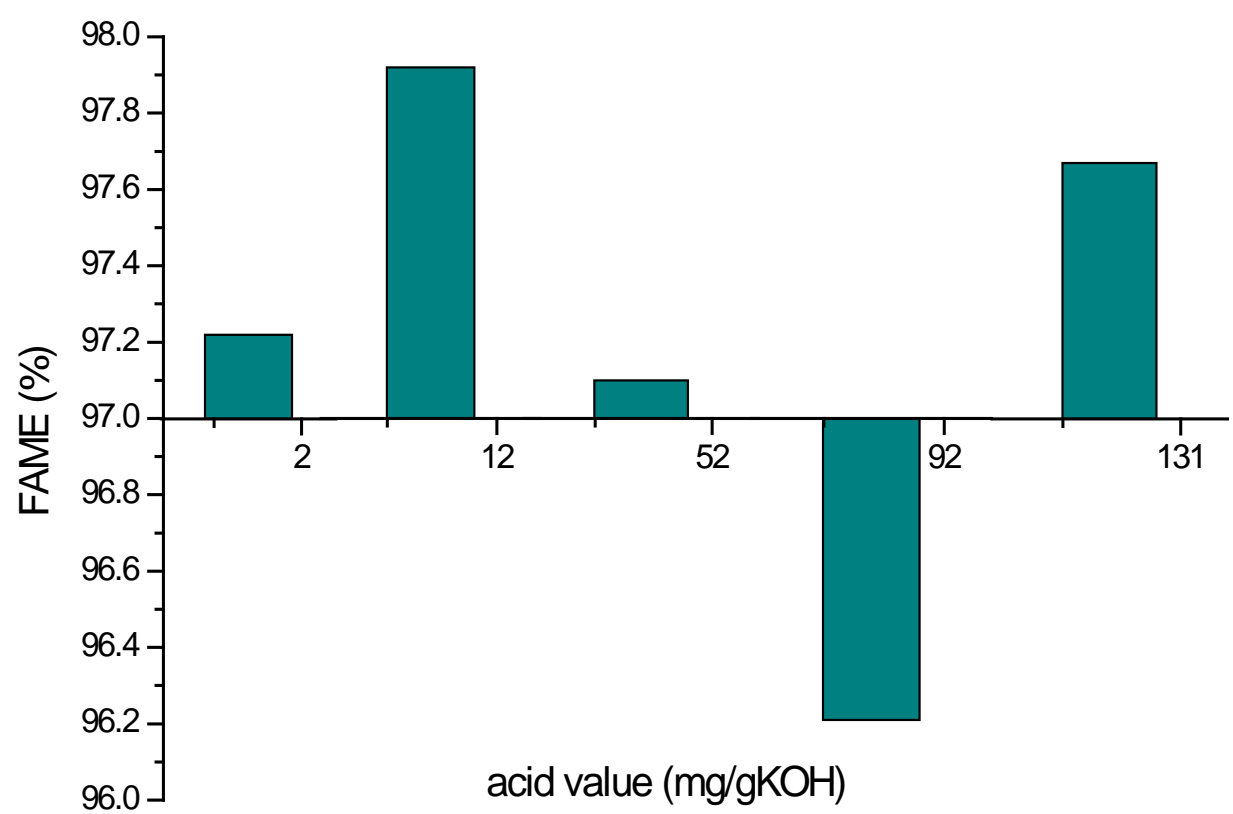

Figure 7. The influence of acid value on the content of fatty acid methyl ester.

\subsection{An Industry Case of Resource utilization: Converting Waste Oils and Fats to Biodiesel in Kunshan}

Kunshan, in the heart of Yangtze River delta with advanced economy, is an important booming city of industry and commerce into the Shanghai economic circle. It has ranked first for the continuous eight years in the "national small and medium-sized city's comprehensive strength of 100 strong”.

As the more prosperous and densely populated city, catering industry in Kunshan has become increasingly developed with the increasing food waste. By 2012 investigation and analysis on restaurant-kitchen garbage of Kunshan [14], it generated restaurant kitchen garbage nearly to 230t/d. But most of them are sent to feed lots as feed or compost raw materials, few is made into hogwash oil.

With the lack of effective supervision and in the huge economic interests, some abandoned grease from kitchen waste was illegal processing into edible oil and return table, which has taken an increasingly serious threat to the health and life safety. In addition, because of most of restaurants don't install the oil-water separator by regulation in their kitchen, the increase of abandoned grease into the underground pipe network will lead to the network congestion that is inevitable to have harmful impact on superficial layer groundwater and bring some another environment issue.

Thus, based on our novel technology of tubular reaction for producing biodiesel from waste oils and fats, leading by government, broad participation of diverse forces, a kind of practice of conversion efficiency of resource utilization model of waste oils and fats from kitchen waste was used in Kunshan.

Firstly, the garbage classification processing had not been implemented, so the kitchen waste was recycled by government according to certain price (after implementation of the garbage classification processing, then replaced by kitchen waste processing units), and free installation oil-water separator for the major catering enterprises to ensure the quality of recycled waste oil. At the same time, the kitchen waste sell to kitchen waste treatment units in low price, proceeds use to maintain the balance of kitchen waste recycling. Then waste oil and fats (other products processing by themselves) obtain form kitchen waste company are purchased by the relevant government departments in higher than the market price, in order to ease the pressure on kitchen waste collection when processing units themselves, and the waste oil and fats sell to downstream professional manufacturer of biodiesel with lower price than market (throughout process, the government no longer provides subsidies to enterprise), and the production enterprise use tubular reactor system to produce biodiesel. In the whole program, on the one hand, the government is responsible for the implementation of waste separation, on the other hand, is responsible for ensuring the quality of recycled waste oil, while monitor all aspects of the whole process in col- 
lection, transportation, separation, transformation and sale. While the funds originally used to maintain the kitchen waste recycling and buy waste oil, in order to improve enterprise's incentive to produce, there are not direct subsidies to enterprises. In addition, biodiesel production enterprises get the raw material which discount on prices from the government, so they should priority supply garbage collection vehicles at cost price to support the work of government, and the remaining products should supply to government vehicles and public transport systems to improve biodiesel the breadth and depth of propaganda, and to create conditions for the subsequent market development. The solution process is shown in Figure 8.

\section{Conclusion and Suggestion}

The tubular reactor systems with $\mathrm{ZrO}_{2}$ Polycrystalline foam ceramic catalyst can easily transform the waste oil and fats to biodiesel, and successfully solve the problems that exist in the traditional production process, reduce the production cost of biodiesel, realize the clean production of biodiesel, while food safety problems caused by waste oil back to the table has also been well resolved. In addition, in Kunshan, for example, the proposed food waste treatment program aimed at the development of waste oil and fats resources for biodiesel production to solve our growing problem of urban waste pollution problems, through the program can guarantee a stable raw material for biodiesel production source, and the program also provides a model for product sales of biodiesel. However, the mold of kitchen waste treatment is difficult to quote directly from one city to another, because in our country, different regions have different economic development, energy demand, policies and regulations as well as the diet culture and so on. In order to push forward development of biodiesel and improve the level of kitchen waste resource utilization in our country, our government should implement garbage classification processing as soon as possible, and introduce dealing with related rules and regulations of kitchen waste treatment at the national level. While strengthening policy support to kitchen waste treatment enterprises, strengthening energy saving environmentally friendly promotional, providing technical and financial support for bio-

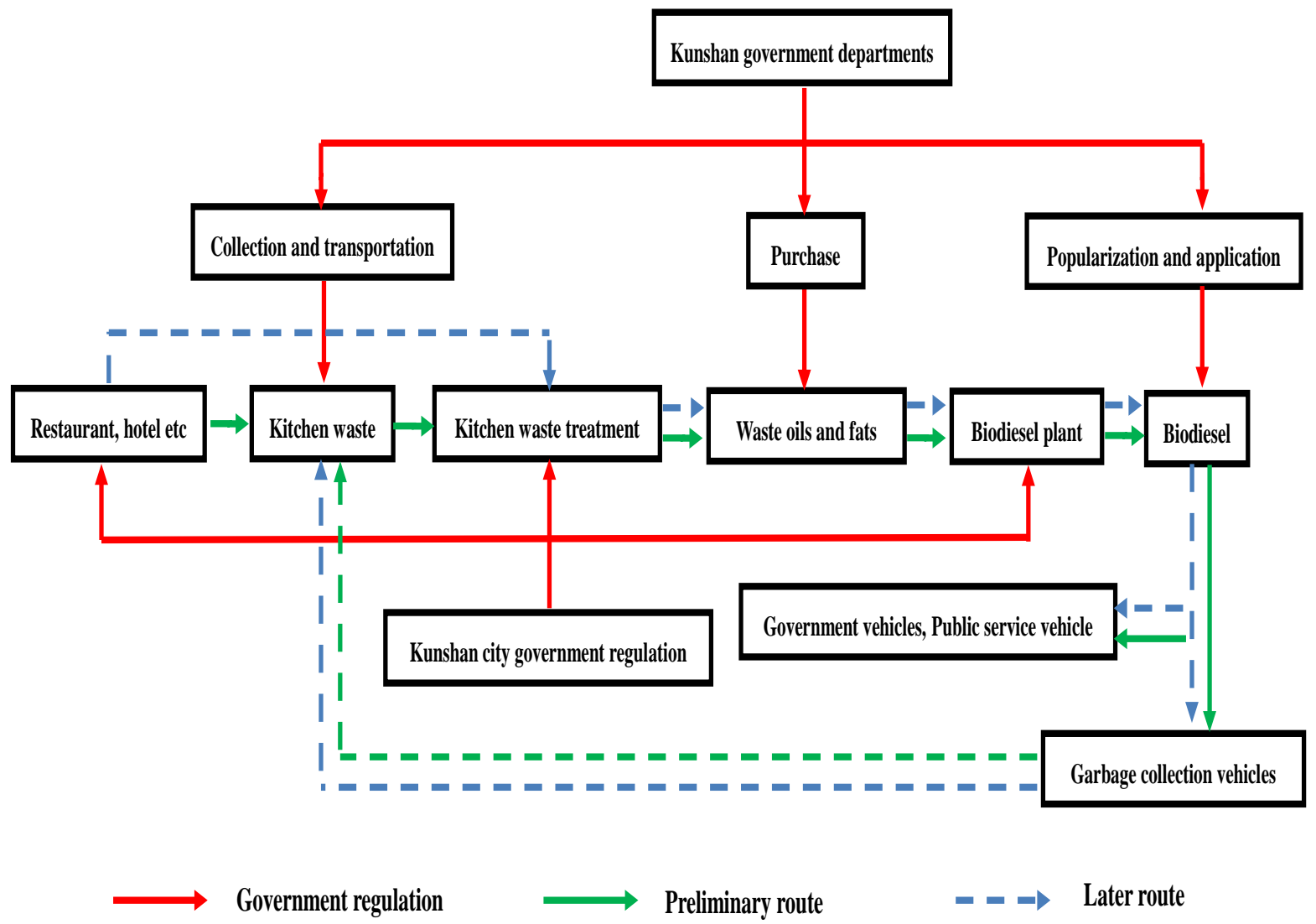

Figure 8. Practice of conversion efficiency of resource utilization model of waste oils and fats from kitchen waste. 
diesel enterprise technical renovation and upgrade, and enact policies to promote bio-diesel into the oil market.

\section{Acknowledgements}

Thanks for the financial support of JSPS (Japan Society for the Promotion of Science) postdoctoral fellowship for foreign researcher.

\section{References}

[1] Zhang, G.J. (2004) The Research on Using Trickle-Bed Reactor to Produce Biodiesel. Master Thesis, Nanjing Industrial University, Nanjing. http://dx.doi.org/10.7666/d.y672274

[2] Frederic, S. and Elisabeth, V. (1994) Vegetable Oil Methyl Ester as a Diesel Substitute. Chemical Industry, 7, $863-865$.

[3] U.S. Energy Information Administration (2011) International Energy Statistics. http://www.eia.gov/cfapps/ipdbproject/IEDIndex3.cfm?tid=79\&pid=79\&aid=1

[4] Liao, L., Yang, M., Yao, J.J., Cheng, W. and Huang, F.H. (2008) Status and Prospect of Bio-Diesel Industry. Chemical Industry and Engineering Progress, 27, 37-41.

[5] International Energy Agency (2014) People’s Republic of China: Oil for 2011. http://www.iea.org/statistics/statisticssearch/report/?country=CHINA\&product=oil\&year=2011

[6] Wang, Q., Wei, X.Q. and Yang, Y. (2010) Industry Chain of Bio-Diesel from the Perspective of Developing Bottleneck and Countermeasure. Future and Development, 8, 52-54. http://dx.doi.org/10.3969/j.issn.1003-0166.2010.08.010

[7] Lai, H.X., Wan, X. and Jiang, M.L. (2010) Advance in Production Technology of Biodiesel. Chemistry \& Bioengineering, 27, 11-15.

[8] Ma, F. and Hanna, M.A. (1999) Biodiesel Production: A Review. Bioresource Technology, 70, 1-15. http://dx.doi.org/10.1016/S0960-8524(99)00025-5

[9] McNeff, C.V., McNeff, L.C., Yan, B.W., Nowlan, D.T., Rasmussen, M., Gyberg, A.E., et al. (2008) A Continuous Catalytic System for Biodiesel Production. Applied Catalysis A: General, 343, 39-48. http://dx.doi.org/10.1016/j.apcata.2008.03.019

[10] McNeff, C.V. (2010) The Green Miracle. http://www.evercatfuels.com/greenmiracle.asp

[11] Guo, P.M., Huang, F.H. and Huang, Q.D. (2006) Preparation of Biodiesel from Waste Oil with High Acid Value. China Oils and Fats, 31, 66-69. http://dx.doi.org/10.3321/j.issn:1003-7969.2006.07.020

[12] Du, Z.X., Zhong, T., Wang, H.J., Zeng, J.L., Chen, Y.F. and Min, E.Z. (2013) Research and Development of a Sub-Critical Methanol Alcoholysis Process for Producing Biodiesel Using Waste Oils and Fats. Chinese Journal of Catalysis, 34, 101-115. http://dx.doi.org/10.1016/S1872-2067(11)60490-7

[13] Zhang, A.H., Xiao, Z.H., Zhang, Y.J., Li, C.Z. and Chen, J.L. (2009) Pre-Esterification of Waste Oil and Study on Preparation of Bio-Diesel. Cereals and Oils Processing, 12, 94-98.

[14] Kunshan Environmental Protection Bureau (2012) The Kunshan Kitchen Waste Survey Report. http://www.ksepb.gov.cn/tzgz/xmsp/gs/201307/t20130715_21033.html 